\title{
Normal Pressure Hydrocephalus Caused by a Spinal Neurinoma at the Cauda Equina Level: A Case Report
}

\author{
Daisuke WAJIMA, ${ }^{1}$ Yuki IDA, ${ }^{1}$ Takuo INUI, ${ }^{2}$ and Hiroyuki NAKASE ${ }^{3}$ \\ ${ }^{1}$ Department of Neurosurgery, Nabari City Hospital, Nabari, Mie; \\ ${ }^{2}$ Department of Neurosurgery, Meijibashi Hospital, Matsubara, Osaka; \\ ${ }^{3}$ Department of Neurosurgery, Nara Medical University School of Medicine, Kashihara, Nara
}

\begin{abstract}
Neurinomas are common space-occupying lesions located in the spinal canal. Many reports concerning their clinical characteristics, diagnoses, treatments, and operative results have been published. Some case reports have discussed spinal neurinomas located at the cauda equina level. However, there is little information on their natural history. Here, we report a case of spinal neurinoma located at the cauda equina level, which caused normal pressure hydrocephalus (NPH). All symptoms resulting from the NPH were resolved by tumor removal. These findings suggested that if a spinal neurinoma located at the cauda equina level causes symptoms due to NPH, then removal of the tumor should be considered, when appropriate removal procedures are possible.
\end{abstract}

Key words: neurinoma, cauda equina, normal pressure hydrocephalus

\section{Case Report}

An 82-year-old man with hypertension complained of months of progressive gait disturbance, dementia, and intermittent urinary incontinence, without headache. Physical examination revealed moderate muscle atrophy in both limbs, hypesthesia of the lateral side of both thighs, and decreased patella and Achilles tendon reflexes. Computed tomography (CT) of the head revealed ventricular dilatation (Fig. 1A). A lumbar puncture was performed. The cerebrospinal fluid (CSF) pressure was $100 \mathrm{mmH}_{2} \mathrm{O}$, and it appeared xanthochromic. CSF analysis showed a high protein level $(0.667 \mathrm{~g} / \mathrm{L})$ and normal cell counts (9/3 cells $\left./ \mathrm{mm}^{3}\right)$.

Lumbar spinal magnetic resonance imaging (MRI) were conducted in order to examine the patient for normal pressure hydrocephalus (NPH), and the imaging demonstrated a well-demarcated intradural tumor in the cauda equina at the L1-L2 level (Fig. 1B). The tumor, which exhibited marked enhancement after the intravenous administration of gadolinium, compressed the nerves at the cauda equina level. CT myelography revealed total blockage of the CSF by the tumor (Fig. 1C).

The patient underwent an operation for tumor removal. After a posterior L1-L2 laminectomy and a Th12 partial laminectomy, the dural sac was opened, and cloudy arach-

Received October 15, 2012; Accepted April 2, 2013 noid membrane at the caudal side of the tumor was found (Fig. 2). After dissection of this arachnoid membrane, the tumor compressed the nerves of the cauda equina. The CSF from the caudal side of the tumor appeared cloudy and xanthochromic. However, the CSF on the cranial side of the tumor appeared watery clear and colorless. The tumor had arisen from a root of the cauda equina, and electrical stimulations confirmed that the root was not a motor root of the limbs. Total removal was performed including the root. A histological examination of the tumor showed typical features of a benign neurinoma (Fig. 3A, B).

Postoperative neurological findings were marked by the progressive recovery of recent memory loss, sensory deficits of the lower limbs, diminished limb reflexes, and persistence of urinary disturbances. Total removal of the tumor was confirmed with CT and MRI (Fig. 4B).

A lumbar puncture was performed 2 weeks after the surgery, and CSF analysis showed a decreased protein level $(0.1 \mathrm{~g} / \mathrm{L})$ and normal cell counts $\left(5 / 3 \mathrm{cells} / \mathrm{mm}^{3}\right)$. Three months after the surgery, a head CT showed reduction in ventricular size (Fig. 4A), and no other symptom of NPH was observed.

\section{Discussion}

We encountered a surgical case of a spinal neurinoma located at the cauda equina. This pathology involved of 


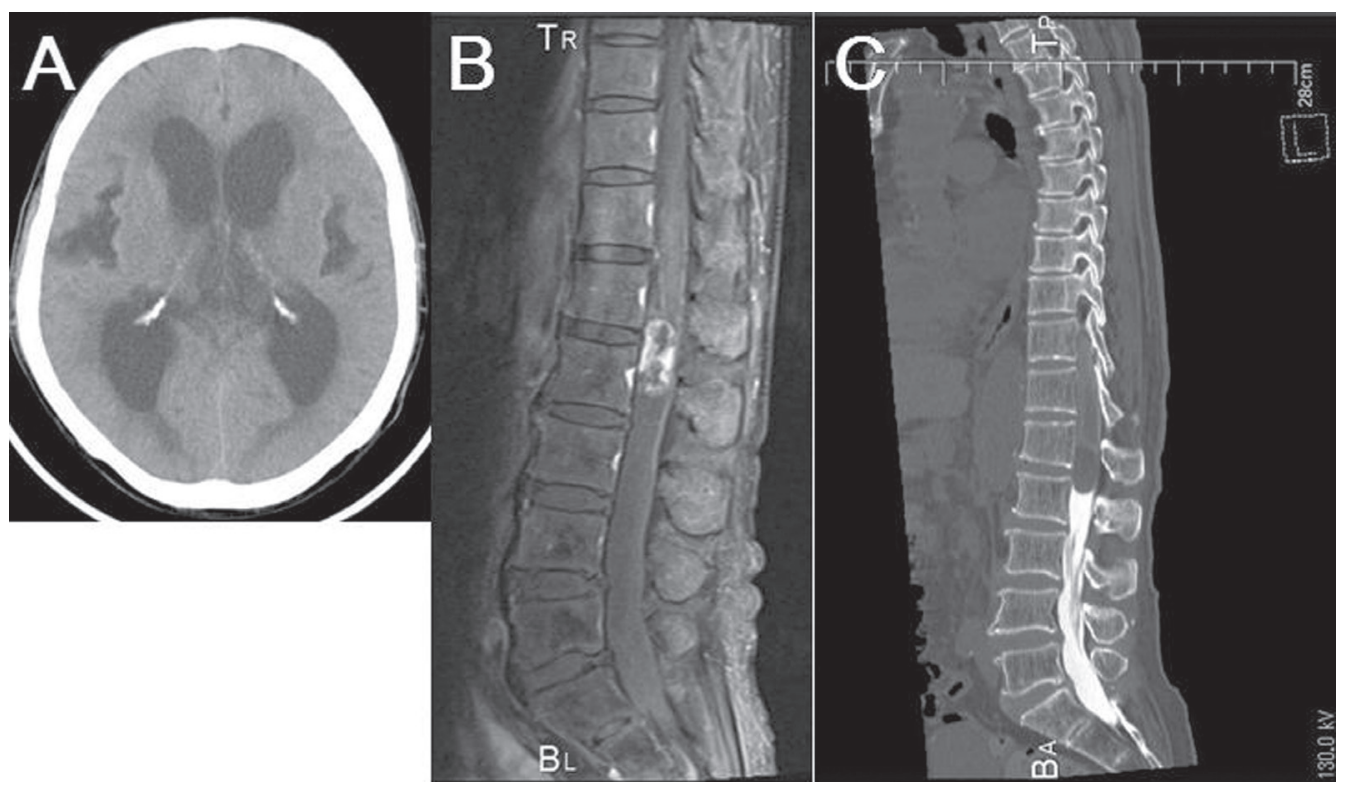

Fig. 1 Preoperative neuroimages of our case. A: Head computed tomography (CT) shows large ventricles and a poor depiction of the cerebral sulcus. B: The mass lesion was enhanced with gadolinium. C: A CT myelogram shows a mass lesion blocking cerebrospinal fluid flow at the L1-2 level.

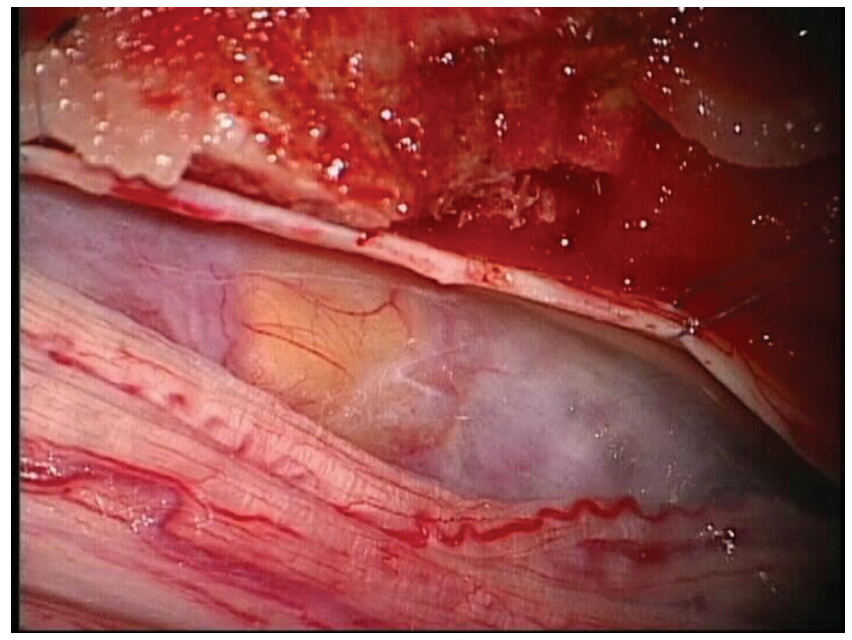

Fig. 2 Intraoperative findings of our case. After opening of the dura, the tumor and a whitish arachnoid membrane were observed.

a typical benign neurinoma, which was associated with $\mathrm{NPH}$, and all of the patient's symptoms were resolved by tumor removal. The symptom triad of NPH is usually described as gait disturbance, dementia, and urinary incontinence. ${ }^{1)}$ In our case, NPH was assumed from the results of an initial head CT and the normal CSF pressure found with a lumbar tap. Idiopathic NPH is often treated with ventricular-peritoneal (VP) or lumbarperitoneal (LP) shunts. However, NPH that is caused by a spinal tumor, as in our case, cannot be treated with VP or LP shunts, because its high protein level of CSF would make obstruction of the shunt system. For this reason, NPH caused by spinal tumors should be treated differently. In many of the previously reported cases of NPHs associated with spinal neurinomas, tumors have been located within the cauda equina region (Table 1). In most cases, only tumor removal improved the patient's symptoms (Table 1). If NPH caused by a spinal tumor is suspected on the basis of the results of a lumbar tap, a lumbar MRI is needed to determine if a spinal tumor is present.

There are many hypotheses concerning the mechanisms by which spinal tumors cause hydrocephalus. ${ }^{1-6)}$ In our case, the cerebrospinal canal was almost completely blocked by the tumor, and an old subarachnoid hemorrhage was observed. This occurs in Fincher's syndrome, which is characterized by bloody spinal fluid due to hemorrhage from a spinal tumor and a choked disc.

The most widely accepted hypothesis about the cause of hydrocephalus is that increased levels of spinal CSF protein or its fractions delay the absorption of spinal fluid. ${ }^{1,3)}$ Table 1, which lists past reports of NPH associated with spinal neurinomas, reveals that many cases showed high levels of CSF proteins. Patients with Landry-Guillain-Barre syndrome who had hydrocephalus and choked discs exhibit symptoms that are very similar to those of patients with hydrocephalus due to spinal tumors. ${ }^{7,8)}$ This implicates the increased levels of CSF proteins in the onset of the hydrocephalus. Various mechanisms have been proposed to explain the increased CSF protein level. According to one theory, ${ }^{9}{ }^{9}$ the tumor itself releases a substance that causes the protein levels to rise. Another hypothesis holds that the protein increase is mediated by immunological factors because increased levels of gamma immunoglobulin have been found in the spinal fluid obtained from patients with 


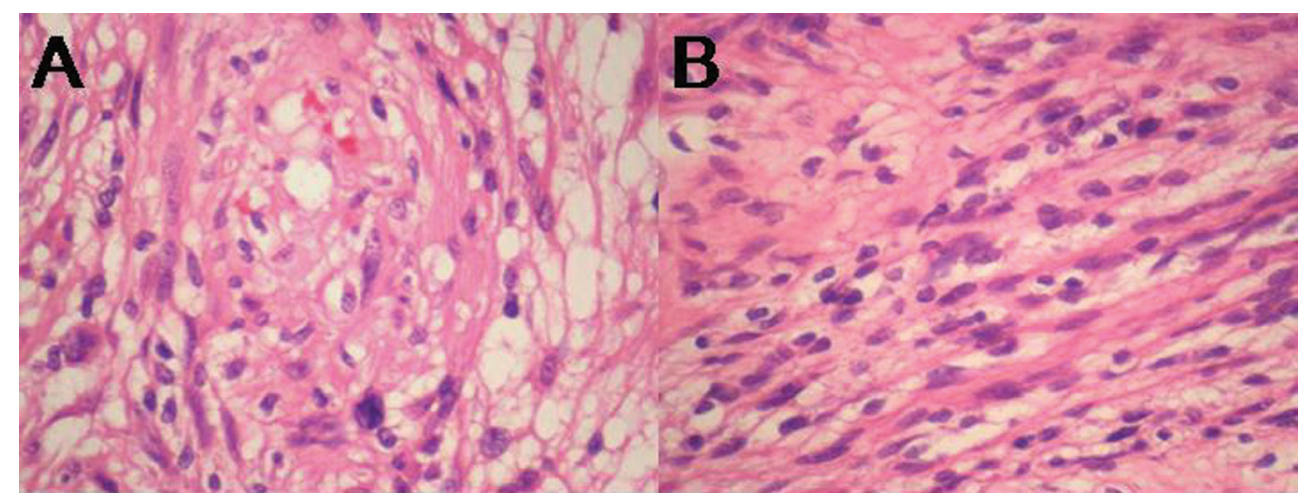

Fig. 3 Pathological findings of our case. Mixed components of Antoni B (400x) (A) and Antoni A (400x) (B). No malignant cells were found in these specimens.

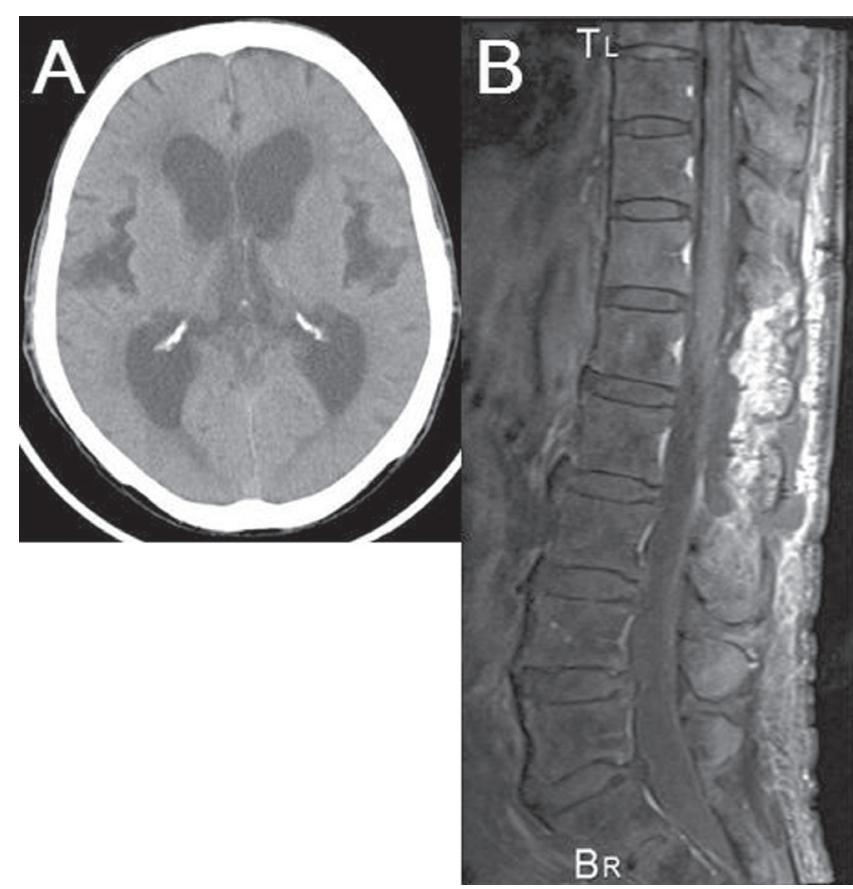

Fig. 4 Postoperative neuroimages of our case. A: A computed tomography of the head shows a slight reduction in ventricular size and a clear depiction of the cerebral sulcus. B: Total removal of the tumor was confirmed by magnetic resonance imaging with gadolinium.

spinal cord tumors accompanied by hydrocephalus. ${ }^{3)}$ Moreover, in many reported cases, tumor removal has been followed by a normalization or reduction in the protein levels, the disappearance of the hydrocephalus, and improvement of the symptoms of NPH. In our case, the symptom of recent memory loss was improved after tumor removal, the CSF protein levels decreased from 0.667 to $0.1 \mathrm{~g} / \mathrm{L} 2$ weeks after the surgery. A reduction of ventricular size was observed 3 months after the surgery (Fig. 4A).

Another popular hypothesis ${ }^{10)}$ about the cause of hydrocephalus is based on the compensatory equilibrium between the spinal CSF compartment and the intracranial vascular pool. Morandi et al. ${ }^{10)}$ have suggested that hydrocephalus in patients with benign intraspinal tumors is the result of a reduction in spinal compliance due to tumoral obstruction of the spinal subarachnoid space, which reduces the total CSF compartment compliance. After tumor removal, recovery can be explained by the return of normal spinal compliance. In our case, the latter hypothesis is more valid than the former hypothesis because the hydrocephalus disappeared after tumor removal.

Although the clinical courses of cauda equina tumors are generally progressive, several authors have described cases involving remissions and relapses. ${ }^{6,7)}$ Recurrent intratumoral hemorrhages and the tumors' mobile characteristics are thought to be the cause of the remissions and relapses. ${ }^{11,12)}$

Regarding the surgical procedures for cauda equina tumors, some authors have expressed concern about possible neurological deficits that result from resection of the root from which the cauda equina tumors arise. ${ }^{13-16)}$ However, tumor removal that includes the involved roots does not always result in postoperative neurological deficits. Moreover, neurinomas usually arise from the dorsal roots, which show less neurological deficits than the ventral roots if they are damaged, and postoperative neurological deficits are rare after root resection. ${ }^{17,18)}$ In our case, the roots from which the tumor arose were resected after confirmation by electronic stimulation that they were not motor roots. Intraoperative electric stimulation was useful for the prevention of motor root injury after removal of the tumor.

\section{Conclusion}

Spinal neurinomas in the cauda equina can cause several symptoms according to their sizes or locations. In particular, they tend to be overlooked as a possible cause of NPH due to disturbances of the CSF circulation. Tumor removal can be sufficient to resolve all symptoms due to the tumors, even if they are associated with NPH. 
Table 1 Reported cases of normal pressure hydrocephalus associated with spinal neurinomas

\begin{tabular}{|c|c|c|c|c|c|}
\hline Author (year) & Age/Sex & Location & CSF protein (g/dl) & Treatment & Outcome \\
\hline Ridsdale et al. (1978) ${ }^{19)}$ & $62 / \mathrm{F}$ & $\mathrm{L} 2-3$ & 2 & Tumor removal+VPS & Improved \\
\hline Messer \& Brinker $(1980)^{20)}$ & $73 / \mathrm{F}$ & Th11-L1 & 1.2 & Tumor removal & Improved \\
\hline Feldmann et al. $(1986)^{21)}$ & $68 / \mathrm{F}$ & $\mathrm{L} 2-4$ & 0.121 & Tumor removal & Improved \\
\hline \multirow[t]{2}{*}{ Kudo et al. $(1987)^{22)}$} & $55 / F$ & $\mathrm{C} 2-4$ & 0.98 & Tumor removal & Improved \\
\hline & $49 / F$ & Th12 & 3 & Tumor removal+VPS & Improved \\
\hline Zavala et al. (1988) ${ }^{23)}$ & $71 / \mathrm{F}$ & Th11-12 & 1.5 & Tumor removal & Improved \\
\hline Nishida et al. $(1990)^{24)}$ & $45 / \mathrm{M}$ & L5-S2 & 0.64 & Tumor removal & Improved \\
\hline Ohta et al. $(1990)^{25)}$ & $65 / F$ & $\mathrm{~L} 2-4$ & 0.868 & Tumor removal & Improved \\
\hline Tourniaire et al. (1993) ${ }^{26)}$ & $76 / \mathrm{M}$ & L5 & 3.062 & Tumor removal+VPS & Improved \\
\hline Sugaya et al. (1993) ${ }^{27)}$ & $69 / F$ & L1 & 4.073 & Tumor removal & Improved \\
\hline Munakata et al. (2002) ${ }^{28)}$ & $69 / F$ & L4-S1 & 2.97 & Tumor removal & Improved \\
\hline Fuse et al. $(2012)^{29)}$ & $70 / \mathrm{M}$ & L1-2, L5 & 0.365 & Tumor removal & Improved \\
\hline Present case & $82 / \mathrm{M}$ & L1-2 & 0.667 & Tumor removal & Improved \\
\hline
\end{tabular}

CSF: cerebral spinal fluid, F: female, M: male, VPS: ventricular-peritoneal shunt.

\section{Conflicts of Interest Disclosure}

The authors have no conflicting interest.

\section{References}

1) Arseni C, Maretsis M: Tumors of the lower spinal cord associated with increased intracranial pressure and papilledema. J Neurosurg 27: 105-110, 1967

2) Gardner WJ, Spitler DK, Whitten C: Increased intracranial pressure caused by increased protein content in the cerebrospinal fluid; an explanation of papilledema in certain cases of small intracranial and intraspinal tumors, and in the Guillain-Barre syndrome. N Engl J Med 250: 932-936, 1954

3) Gibberd FB, Ngan H, Swann GF: Hydrocephalus, subarachnoid haemorrhage and ependymomas of the cauda equina. Clin Radiol 23: 422-426, 1972

4) Glasauer FE: Thoracic and lumbar intraspinal tumours associated with increased intracranial pressure. J Neurol Neurosurg Psychiatry 27: 451-458, 1964

5) Love JG, Wagener HP, Woltman HW: Tumor of the spinal cord associated with choking of optic disks. AMA Arch Neur Psych 66: 171-177, 1951

6) Norstrom CW, Kernohan JW, Love JG: One hundred primary caudal tumors. JAMA 178: 1071-1077, 1961

7) Joynt RJ: Mechanism of production of papilledema in GuillainBarre syndrome. Neurology (Minneap) 8: 8-12, 1958

8) Morley JB, Reynolds EH: Papilloedema and the LandryGuillain-Barré syndrome. Case reports and a review. Brain 89: 205-222, 1966

9) Hamlat A, Abderrahmane H, Sid-Ahmed S, Seddik SA, Adn M, Mahmoudreza A, Askar B, Brahim A, Pasqualini E, Edouardo P: Idiopathic normal pressure hydrocephalus: theoretical concept of a spinal etiology. Med Hypotheses 67: 110-114, 2006

10) Morandi X, Amlashi SF, Riffaud L: A dynamic theory for hydrocephalus revealing benign intraspinal tumours: tumoural obstruction of the spinal subarachnoid space reduces total CSF compartment compliance. Med Hypotheses 67: 79-81, 2006

11) HogenEsch RI, Staal MJ: Tumors of the cauda equina: the importance of an early diagnosis. Clin Neurol Neurosurg 90: $343-348,1988$

12) Hollin SA, Drapkin AJ, Wancier J, Huang YP: Mobile schwannoma of the cauda equina. Case report. J Neurosurg 48: 135-137, 1978

13) Gautier-Smith PC: Clinical aspects of spinal neurofibromas. Brain 90: 359-394, 1967

14) Iraci G, Peserico L, Salar G: Intraspinal neurinomas and meningiomas. A clinical survey of 172 cases. Int Surg 56: 289-303, 1971

15) Milnes JN: The early diagnosis of tumors of the cauda equina. J Neurol Neurosurg Psychiatry 16: 158-165, 1953

16) Salah S, Horcajada J, Perneczky A: Spinal neurinomas.-a comprehensive clinical and statistical study on 47 cases. Neurochirurgia (Stuttg) 18: 77-84, 1975

17) Hanakita J, Suwa H, Nagayasu S, Nishi S, Iihara K, Sakaida H: Clinical features of intradural neurinomas in the cauda equina and around the conus medullaris. Neurochirurgia (Stuttg) 35: 145-149, 1992

18) Kim P, Ebersold MJ, Onofrio BM, Quast LM: Surgery of spinal nerve schwannoma. Risk of neurological deficit after resection of involved root. J Neurosurg 71: 810-814, 1989

19) Ridsdale L, Moseley I: Thoracolumbar intraspinal tumours presenting features of raised intracranial pressure. J Neurol Neurosurg Psychiatry 41: 737-745, 1978

20) Messer HD, Brinker RA: Hydrocephalus and dementia complicating spinal tumor. Case report. J Neurosurg 53: 544-547, 
1980

21) Feldmann E, Bromfield E, Navia B, Pasternak GW, Posner JB: Hydrocephalic dementia and spinal cord tumor. Report of a case and review of the literature. Arch Neurol 43: 714-718, 1986

22) Kudo H, Tamaki N, Kim S, Shirataki K, Matsumoto S: Intraspinal tumors associated with hydrocephalus. Neurosurgery 21: 726-731, 1987

23) Zavala LM, Adler JR, Greene CS, Winston KR: Hydrocephalus and intraspinal tumor. Neurosurgery 22: 751-754, 1988

24) Nishida K, Ueda S, Matsumoto K, Kusaka K, Takeuchi R: Cauda equina neurinoma associated with normal pressure hydrocephalus-case report. Neuro Med Chir (Tokyo) 30: 258-262, 1990

25) Ohta K, Gotoh F, Amano T, Obara K: Normal pressure hydrocephalus associated with cauda equina neurinoma. Ann Neurol 27: 441-443, 1990

26) Tourniaire D, Sankey R, Pagès M, Privat JM, Blard JM, Labauge R: [Normal pressure hydrocephalus and lumbar neurinoma].
Rev Neurol (Paris) 149: 802-804, 1993 (French)

27) Sugaya M, Noguchi M, Tsutsumi Y: [Neurinoma of the cauda equina associated with normal pressure hydrocephalus]. No To Shinkei 45: 871-875, 1993 (Japanese)

28) Munakata S, Nagumo K, Tanno T, Kojima S: [A case of parkinsonian syndrome caused by normal pressure hydrocephalus accompanied by the cauda equina neurinoma]. Rinsho Shinkeigaku: 42: 131-135, 2002 (Japanese)

29) Fuse A, Nishioka K, Shimura H, Manabe W, Tanaka R, Hattori N, Urabe T: Resection of multiple neurinomas of the cauda equina improves normal pressure hydrocephalus. Open J Modern Neurosurg 2: 54-57, 2012

Address reprint requests to: Daisuke Wajima, MD, $\mathrm{PhD}$, Department of Neurosurgery, Nabari City Hospital, 1-178 YurigaokaNishi, Nabari, Mie 518-0481, Japan.

e-mail: superjocky2@hotmail.com 